\title{
Southern high-latitude Digisonde observations of ionosphere E-region Bragg scatter during intense lacuna conditions
}

\author{
D. P. Monselesan ${ }^{1,2}$, R. J. Morris ${ }^{1}$, P. L. Dyson ${ }^{3}$, and M. R. Hyde ${ }^{1,2}$ \\ ${ }^{1}$ Australian Antarctic Division, Kingston, Tasmania, Australia \\ ${ }^{2}$ IPS Radio and Space Services, Haymarket, New South Wales, Australia \\ ${ }^{3}$ Department of Physics, La Trobe University, Bundoora, Victoria, Australia
}

Received: 5 December 2003 - Revised: 5 May 2004 - Accepted: 14 May 2004 - Published: 7 September 2004

\begin{abstract}
During summer months at solar cycle minimum, F-region lacuna and slant-Es conditions (SEC) are common features of daytime ionograms recorded around local magnetic noon at Casey, Antarctica. Digisonde measurements of drift velocity height profiles show that the occurrence of lacuna prevents the determination of F-region drift velocities and also affects E-region drift velocity measurements. Unique E-region spectral features revealed as intervals of Bragg scatter superimposed on typical background Eregion reflection were observed in Digisonde Doppler spectra during intense lacuna conditions. Daytime E-region Doppler spectra recorded at carrier frequencies from 1.5 to $2.7 \mathrm{MHz}$, below the E-region critical frequency $\mathrm{f}_{o} \mathrm{E}$, have two side-peaks corresponding to Bragg scatter at approximately $\pm 1-2 \mathrm{~Hz}$ symmetrically located on each side of a centralpeak corresponding to near-zenith total reflections. Angleof-arrival information and ray-tracing simulations show that echo returns are coming from oblique directions most likely resulting from direct backscatter from just below the total reflection height for each sounding frequency. The Bragg backscatter events are shown to manifest during polar lacuna conditions, and to affect the determination of E-region background drift velocities, and as such must be considered when using standard Doppler-sorted interferometry (DSI) techniques to estimate ionospheric drift velocities. Given the Doppler and spatial separation of the echoes determined from high-resolution Doppler measurements, we are able to estimate the Bragg scatter phase velocity independently from the bulk E-region motion. The phase velocity coincides with the $\boldsymbol{E} \times \boldsymbol{B}$ direction derived from in situ fluxgate magnetometer records. When ionospheric refraction is considered, the phase velocity amplitudes deduced from DSI are comparable to the ion-acoustic speed expected in the E-region. We briefly consider the plausibility that these previously unreported polar cap E-region Bragg scatter Doppler spectral signatures, observed at Casey in December 1996 during SEC/lacuna
\end{abstract}

Correspondence to: R. J. Morris

(ray.morris@aad.gov.au) conditions may be linked to ionosphere irregularities. These irregularities may possibly be generated by primary plasma waves triggered by current-driven instabilities, that is to say, a hybrid of the "modified two-stream" and "gradient drift" instability mechanisms.

Key words. Ionosphere (polar ionosphere; ionospheric irregularities; plasma waves and instabilities)

\section{Introduction}

The detection of coherent echoes at HF and VHF frequencies from both equatorial and polar E-regions has a long history, which started with the pioneering work of Eckersley (1937) and Harang and Stoffregen (1938) on high-latitude E-region irregularities. In the equatorial regions, radar experiments in the early 1960s linked coherent echoes to field-aligned irregularities associated with intensifications of the current systems found at these latitudes (Bowles et al., 1960; Cohen et al., 1962 and references therein). Since then, numerous E-region radar observations have been extensively reviewed (e.g. Fejer, 1979; Fejer and Kelley, 1980; Fejer et al., 1984; Fejer, 1996). Sahr and Fejer (1996) reviewed experimental observations of meter scale plasma irregularities in the auroral E-region and the status of current theoretical understanding. These E-region irregularities have been largely explained in terms of coherent scatter from electron density irregularities generated by the gradient-drift (Maeda et al., 1963) and the modified two-stream (Farley, 1963; Buneman, 1963) instabilities.

Sahr and Fejer (1996) reviewed observations from sophisticated HF and VHF radars, however, most digital ionosondes currently in use operate like coherent HF Doppler radars (Haines and Reinisch, 1993; Wright and Pitteway, 1994; MacDougall et al., 1995). They utilize coherent transmission and reception of HF radio pulses to provide unambiguous group range and/or velocity for the ionospheric regions under observation. In this study we report on novel Digisonde 
observations of E-region Bragg scatter signatures observed in the polar cap ionosphere during conditions of lacuna and we suggest that the signatures may be linked to the occurrence of E-region ionospheric irregularities.

The lacuna phenomenon (Piggott and Rawer, 1978) manifests itself by the partial or total, but sudden, disappearance of normal ionogram traces. The affected portions start at the end of the E-region trace, where retarded echoes are usually missing (E-F lacuna), and can extend to both the F1 and $\mathrm{F} 2$ layers (F1 and F2 lacuna). The phenomenon is neither due to equipment failure nor enhanced D-region absorption. The minimum observed frequency fmin remains generally close to the value measured on ionograms recorded before and after the event, and is consistent with normal or slightly enhanced absorption. Normal F-region echoes are replaced by weak returns or are completely absent. Lacuna has been associated with slant sporadic E-traces observed on highlatitude ionograms and are commonly bundled together under the title SEC/lacuna condition (Piggott and Rawer, 1978; Olesen et al., 1986; Olesen, 1998).

This paper presents new observations of E-region Bragg scatter signatures in the daytime polar cap/cusp detected using an UMLCAR Digital Portable Sounder 4 (DPS4) or Digisonde (Haines and Reinisch, 1993; Monselesan et al., 1994) operated by the Australian Antarctic Division at Casey station, Antarctica $\left(66.28^{\circ} \mathrm{S}, 110.52^{\circ} \mathrm{E}, 80.8^{\circ} \mathrm{S}\right.$ corrected geomagnetic latitude, $\mathrm{LT}=\mathrm{UT}+07: 22$ ) (Morris et al., 1995). The Digisonde results are further supported by co-located $30 \mathrm{MHz}$ riometer and magnetometer records.

\section{Instrumentation and study interval}

The Digisonde is a computer-controlled pulse Doppler ionosonde (Haines and Reinisch, 1993) specifically designed for high-latitude ionospheric drift measurements, where large plasma convection velocities prevail. The Digisonde's programming versatility allowed us to devise complex measurement schedules to gather both E- and F-region drift data in separate frequency-range gates aimed at resolving differences in their respective motions.

The study spans two weeks of intensive Digisonde E- and F-region campaign drift measurements performed from 13 to 31 December 1996. Multi-beam ionograms were initiated every $15 \mathrm{~min}$, lasting under $3 \mathrm{~min}$ and followed by a series of four 2-min long E- and F-region drift measurements of ordinary polarization echoes. Each ionogram scan was limited to a frequency range of 1 to $8 \mathrm{MHz}$ covered in $100 \mathrm{kHz}$ steps. At each frequency, a coherent integration of 64 phase-coded pulses at $200 \mathrm{~Hz}$ pulse repetition frequency (PRF) for multiplexed O- and X-modes was performed separately on the system's four receiver antennas for 128 group range gates separated by $5 \mathrm{~km}$ increments starting at a group range of $80 \mathrm{~km}$.

Daytime E-region drift measurement sets use a PRF of $100 \mathrm{~Hz}$ and a multiplex of 8 frequencies per coherent integration lasting $20.48 \mathrm{~s}$, a value four times larger than the smallest
F-region coherent integration time (CIT). The corresponding unambiguous Doppler range of $6.25 \mathrm{~Hz}$ is extremely narrow and leads to a high Doppler resolution of $0.0488 \mathrm{~Hz}$. Each E-region drift measurement spans $1.2 \mathrm{MHz}$ (from 1.5 to $2.7 \mathrm{MHz}$ ) in three coarse steps of $400 \mathrm{kHz}$ with 8 multiplexed frequencies separated by $50 \mathrm{kHz}$ small steps.

Co-located fluxgate magnetometer and wide-beam $30-\mathrm{MHz}$ riometer data were sampled at $0.1 \mathrm{~Hz}$ and complement the Digisonde drift and ionogram records.

\section{Observations}

\subsection{E- and F-region drift velocities}

The velocity profiles over Casey station on the 16 December 1996, obtained using the Drift Data Analysis (DDA) software package developed by Scali et al. (1995) at UMLCAR, which implements the digital sorted interferometry (DSI) technique, are shown in Fig. 1. Each row displays the vertical and horizontal components of the velocity vectors, and the corresponding azimuths (relative to compass north) averaged over three UT hours. F-region drift azimuths follow the general antisunward convection expected at a typical polar cap station, between 06:00 and 15:00 UT. However, Smith et al. (1998) and Morris et al. (2004) demonstrated that Casey station is sufficiently northward of the corrected geomagnetic south-pole, for IMF induced distortions of the convection pattern to be observed in the noon-sector associated with the dayside throat. (MLT at Casey equals UT+05:22 h). Thus, the enhanced horizontal velocities observed at Casey between 00:00 and 06:00 UT were expected, with antisunward flow dominating as the convection system rotated towards dawn, and the IMF $B_{y}$ and $B_{z}$ components turned and remained negative, as observed by the WIND satellite (see Fig. 3 in Smith et al., 1998, and Figs. 3 and 4 in Morris et al., 2004). The daytime profiles (rows 1, 2, 3 and 8) show greater scatter for both velocity components, with the F-region drift most affected. Both the E- and F-region averaged plasma drift velocities were highly variable with respect to group range, especially during daytime. They departed substantially from the highly averaged velocity true-height profiles presented, for example, by Parkinson et al. (1997) and recorded at the same location in March 1996.

All E- and F-region velocity measurements used to compute the averaged height profiles shown in Fig. 1 have been plotted as individual points in Fig. 2. From 02:00 to 06:00 UT, F-region velocity points (displayed in red) suddenly vanish, whereas E-region velocity points (displayed in green) appear to be slightly enhanced. Thus, F-region drift measurements in the 03:00-06:00 UT profile in Fig. 1 correspond to just a short interval of good quality F-region data after 05:00 UT. DDA-analyzed drift data presented in Figs. 1 and 2 provided little information about the physical phenomena responsible for the lack of F-region echoes and the simultaneous enhancement of E-region drift velocities. Following the approach of Wright and Argo (1994), a detailed 


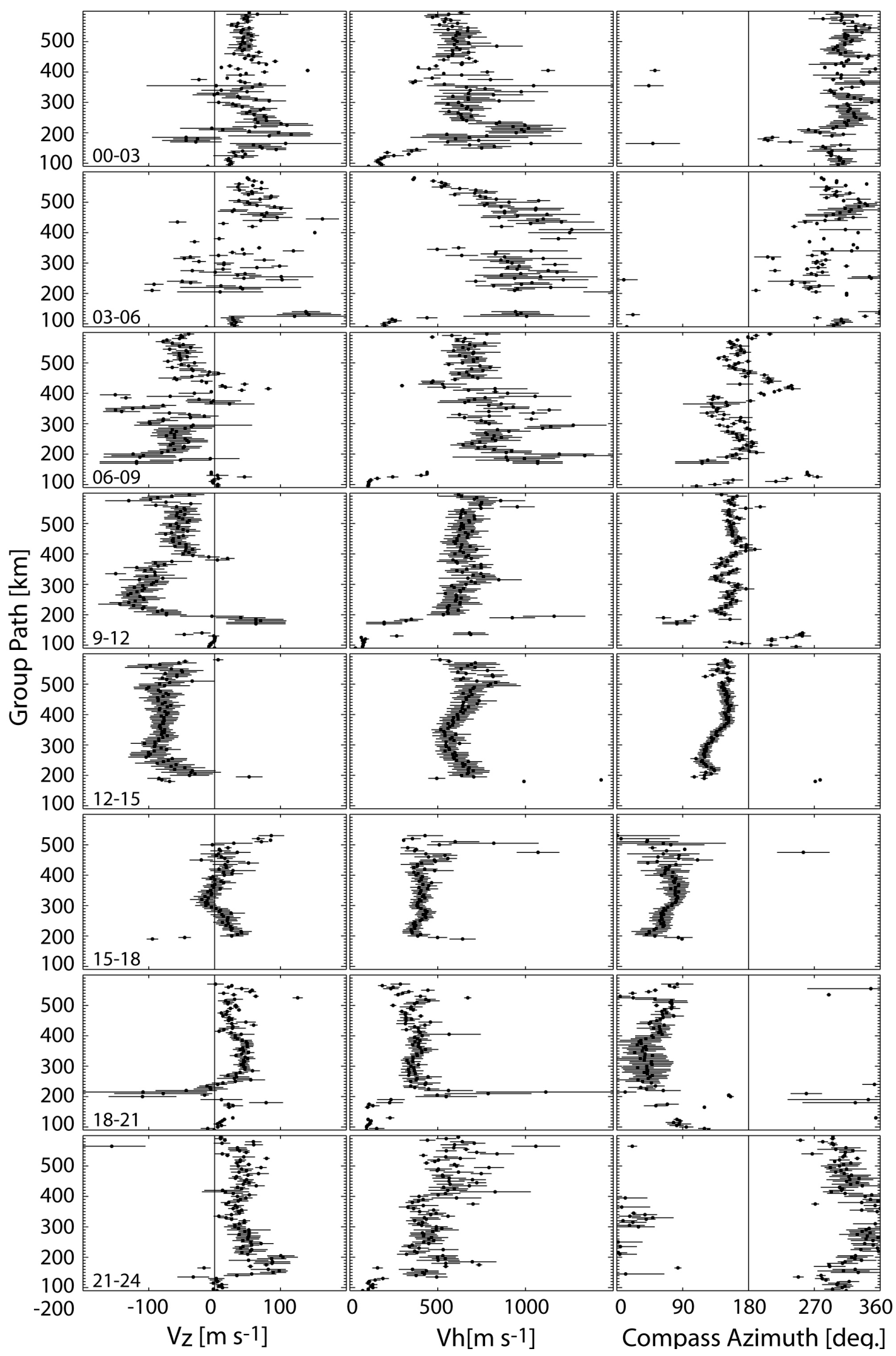

Fig. 1. Three-hourly averaged ionospheric drift velocities recorded over Casey station for 16 December 1996 as a function of the group path. The velocity components are expressed in a compass-oriented coordinate system. Azimuth angles are measured positive eastwards from compass north $\left(\sim 92^{\circ}\right.$ west of geographic north). Large error bars are associated with late morning and early afternoon drift measurements in the 03:00 to 06:00 UT and 06:00 to 09:00 UT time intervals (magnetic local noon corresponds to 06:30 UT at Casey). 

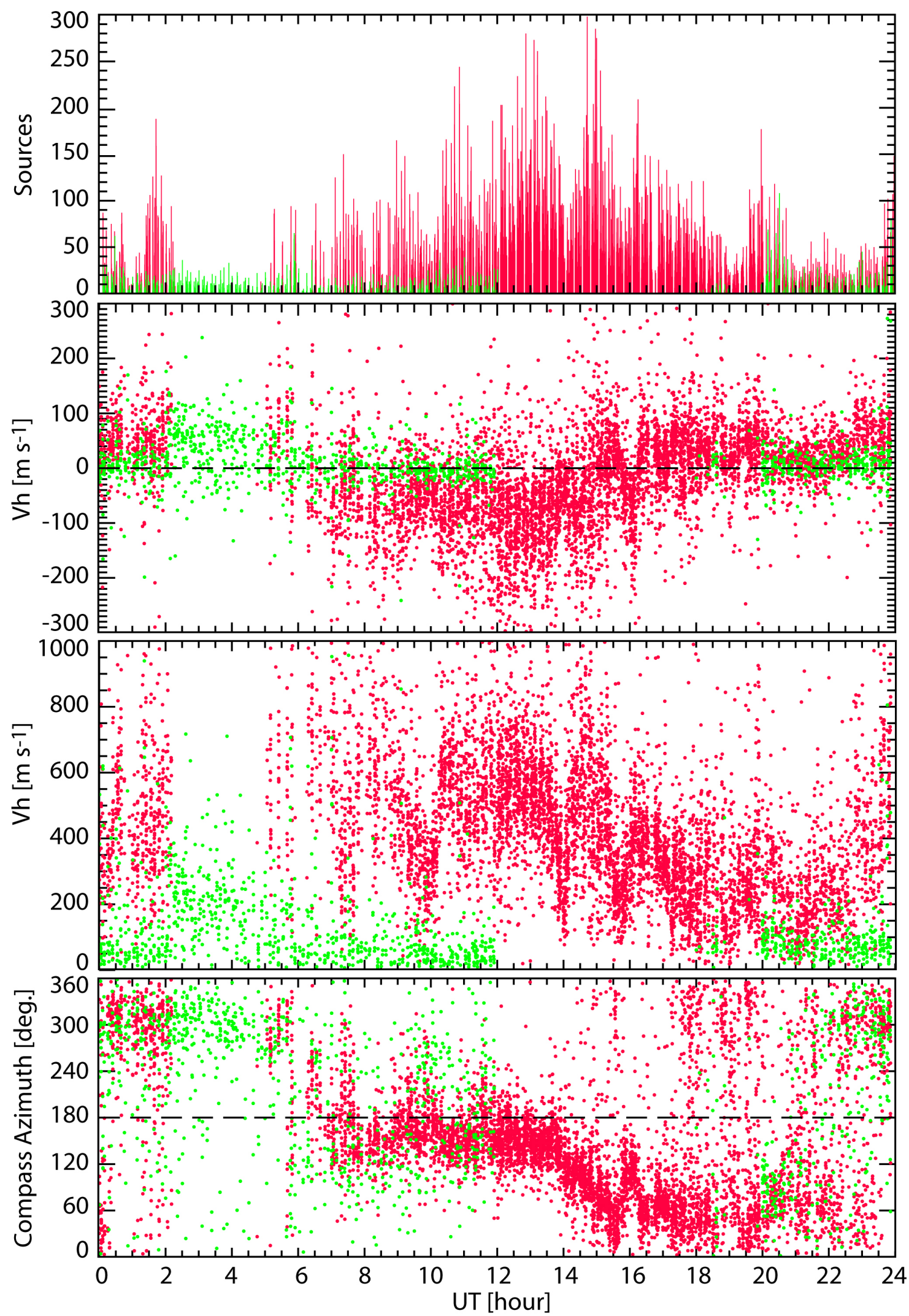

Fig. 2. A compilation of all E- and F-region ionospheric drift measurements recorded over Casey station on 16 December 1996 . The E-region velocities are shown in green, F-region velocities in red. Each velocity point results from the application of the Doppler-sorted interferometry technique, assuming uniform plasma motion over the field-of-view of the radar. The dearth of F-region velocity points and the simultaneous enhancement of E-region drift from 02:00 to 06:00 UT coincide with an intense lacuna condition. 


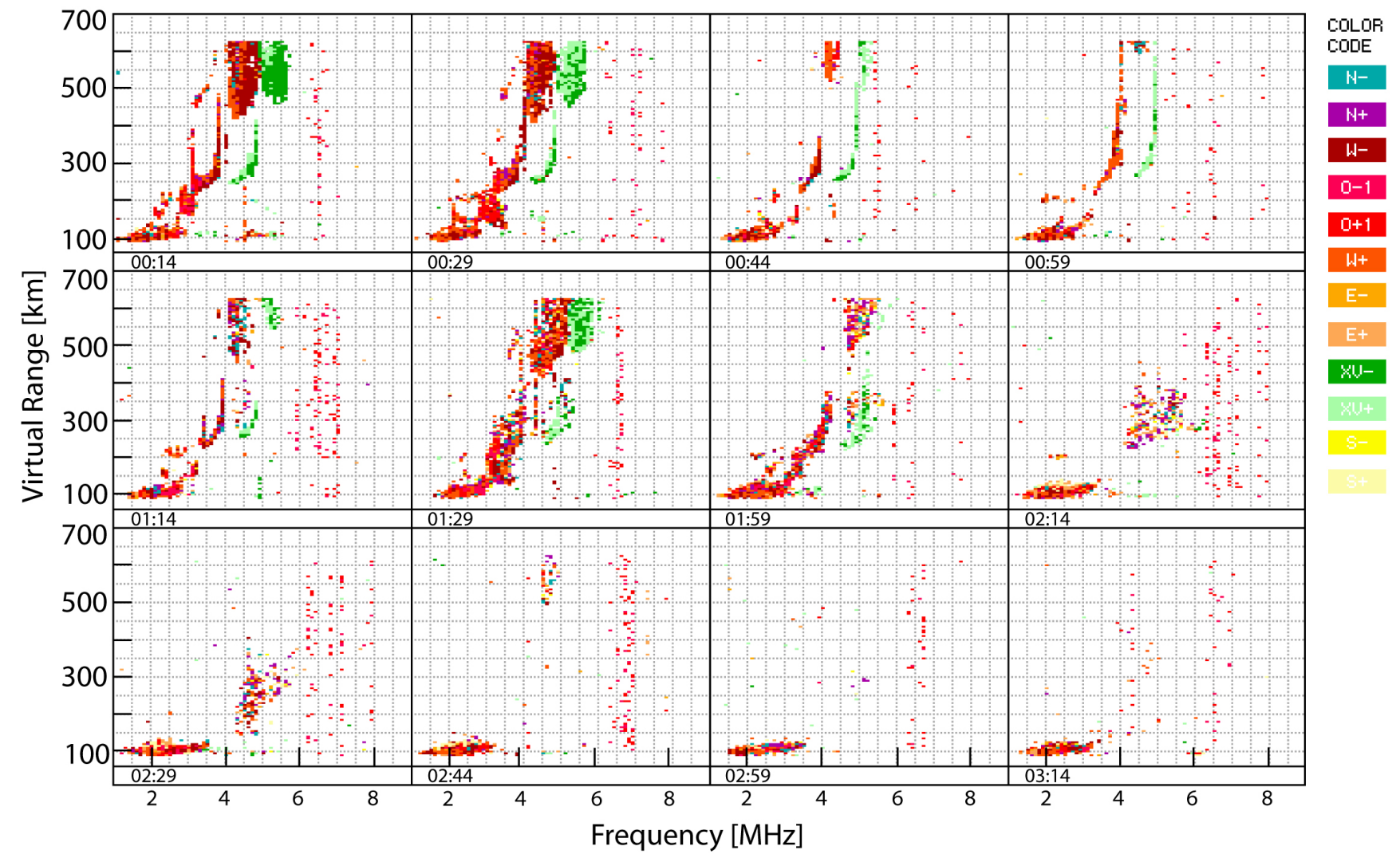

Fig. 3. Multi-beam ionogram records showing the development of a polar cap lacuna condition starting at 01:59 UT and lasting over $4 \mathrm{~h}$ on 16 December 1996. Each ionogram ranges from 1 to $8 \mathrm{MHz}$ in $100 \mathrm{kHz}$ steps. Color-coded and optically weighted fonts provide coarse angle-of-arrival and Doppler information. All cardinal directions are given in a compass-oriented coordinate system. At each sounding frequency, a coherent integration of 64 phase-coded pulses at $200 \mathrm{~Hz}$ PRF for multiplexed O- and X-modes is performed separately on the system four receiver antennas. The coarse frequency and height grid-lines are separated by $0.5 \mathrm{MHz}$ and $50 \mathrm{~km}$, starting from $1 \mathrm{MHz}$ and $60 \mathrm{~km}$, respectively.

analysis of individual Doppler spectra and ionograms was used to shed light on the underlying physical processes and while observations were obtained of both E- and F-region velocities, this paper focuses on specific E-region events.

\subsection{E- and F-region lacuna}

The sequence of 12 consecutive ionograms recorded on 16 December 1996 displayed in Fig. 3, illustrates the development of typical F-region lacuna at Casey near local noon. The condition started around 01:59 UT and persisted for $4 \mathrm{~h}$. The E-region minimum frequency stayed below $1.5 \mathrm{MHz}$ over the entire interval, indicating weak absorption in the D- and lower E-regions. However, faint sporadic E-layers were also present at times (at 00:14, 01:59, 02:14, 02:29 and 02:44 UT), suggesting low-level dayside particle precipitation. As this condition developed the F1- and F2-trace height spread increased between 01:29 and 01:59 UT. At 02:14 UT the F1-trace disappeared completely. The F2-region echo strength also weakened and a diffuse, structureless feature at low group range replaced the F2-region trace. The lack of retardation at the high-frequency end of the E-trace indicates E-region lacuna and the background E-region crit- ical frequency $\mathrm{f}_{o} \mathrm{E}$ cannot be measured accurately. However, the ionogram records show that $\mathrm{f}_{o} \mathrm{E}$ stays above $3 \mathrm{MHz}$ for the entire interval. After 02:29 UT, weak and diffuse F-region echoes appeared sporadically and corresponded to weak oblique echoes in multi-beam ionograms (yellow optically weighted fonts for southern and purple/blue for northern bearings, respectively, in Fig. 3).

The lacuna condition shown in Fig. 3 is obviously responsible for the reduction of F-region echoes, but does not explain the increased E-region velocities shown in Fig. 2. The appearance of daytime E- and F-region lacuna and associated F-region irregularities in ionogram records at Casey, have been a common feature of the high-latitude ionosphere at solar cycle minimum and have impaired the routine measurement of F-region drift. Polar lacuna conditions, listed in Table 1, were present on 15 days out of 19 of the December 1996 campaign. Given the low number of days available to the study, no obvious dependence of the lacuna occurrence and intensity upon magnetic activity and auroral indices, or the IMF, could be clearly established. Figure 4 shows the diurnal and seasonal occurrence distributions for SEC/lacuna as scaled from Casey Digisonde ionogram records for 1996, 
Table 1. Geophysical condition summary for the December 1996 solstice campaign, where the daily $K_{p}$ and $A_{p}$ indices and the SEC/lacuna and E-region Bragg scatter signature intervals are compared. A star indicates data gaps and a dash no observed occurrence. Note that ionograms and E-region drift measurements are initiated every 15 and 7 min respectively, and LT=UT+07:22.

\begin{tabular}{llrll}
\hline DOY & $\Sigma K_{p}$ & $A_{p}$ & E-/F-region lacuna interval (UT) & E-region signature interval (UT) \\
\hline 347 & $17^{-}$ & 8 & $* / 06: 30-07: 00$ & $04: 30-07: 15$ \\
348 & $12^{-}$ & 6 & $04: 30-07: 29$ & $04: 00-07: 00$ \\
349 & $13^{-}$ & 6 & - & - \\
350 & 22 & 13 & $04: 00-04: 45 / 05: 15-05: 45 / 06: 45-08: 15$ & - \\
351 & $21^{-}$ & 12 & $02: 15-04: 30 / * / 08: 30-08: 45$ & $02: 00-06: 00$ \\
352 & $19^{-}$ & 10 & $03: 00-04: 30 / 06: 00-07: 30$ & $03: 00-05: 00$ \\
353 & 12 & 6 & $* / 05: 30$ & $04: 00-04: 15 / 05: 30-05: 45$ \\
354 & $1^{+}$ & 1 & - & - \\
355 & $3^{-}$ & 2 & - & - \\
356 & 12 & 6 & $04: 30 / 07: 30$ & $06: 30-06: 45 / 07: 30-07: 45$ \\
357 & 15 & 9 & $01: 45-02: 15 / 03: 00 / 04: 00 / 04: 45-05: 30$ & $00: 00-00: 30 / 03: 00-06: 00$ \\
358 & $14^{+}$ & 9 & $00: 30-05: 30$ & $00: 00-01: 45 / 03: 45-05: 30$ \\
359 & $8^{-}$ & 4 & $03: 30-05: 15 / *$ & $03: 30-05: 30 / *$ \\
360 & 12 & 6 & $* / 04: 30 / *$ & $* / 04: 30-06: 30$ \\
361 & 6 & 3 & $01: 00-04: 15$ & $00: 45-04: 15 / 06: 45-07: 00$ \\
362 & $6^{+}$ & 3 & $04: 00$ & - \\
363 & $6^{-}$ & 3 & $06: 30$ & - \\
364 & $7^{+}$ & 4 & - & - \\
365 & $18^{-}$ & 10 & $01: 00-02: 00 / 03: 00-05: 45 / 08: 00-08: 30$ & $03: 00-03: 30 / 03: 45-06: 00 / 07: 45-08: 30$ \\
\hline
\end{tabular}

and clearly illustrates a summer daytime maximum in occurrence, consistent with observations from the southern polar cap/cusp station Dumont d'Urville, as reported by Cartron and Vila (1994).

However, multi-beam ionograms recorded during the December 1996 campaign only revealed a low occurrence rate of SEC traces despite the use of the highest receiver gain available. The ionogram coherent integrations were performed over 64 pulses only and at low Doppler resolution (short CIT), to shorten the ionogram completion time to under 3-min and to allow time for various drift measurements. These multi-beam measurement settings were probably inadequate given the diffuse nature of SEC echoes. For comparison, ionogram records collected at Casey on 15 December 1994, with a 128-pulse coherent integration, clearly display SEC echoes in Fig. 5 and emphasize the gain-sensitive nature of SEC and lacuna conditions, as discussed by Olesen (1998).

\subsection{E-region Doppler spectra}

We have shown that F-region drift measurements were heavily compromised during lacuna conditions and F-region drift spectra were featureless. No reliable velocity determination was possible (i.e. the lack of F-region velocity points in Fig. 2 between 02:00 and 06:00 UT). We have also seen that E-region velocity drift measurements were affected. Figure 6 provides a summary of $12 \mathrm{~h}$ of daytime E-region drift Doppler spectral measurements recorded on 16 December 1996 that revealed a unique and previously unreported spectral signature. Inspection of the Doppler spectra showed the sudden appearance of side-peaks, between $\pm 1-2 \mathrm{~Hz}$, symmetrically located on both sides of the main central peak (corresponding to near-zenith total reflections). These features lasted as long as lacuna was present on the ionogram. Note also that the Doppler-shift gap between the central and side-peaks did not increase (decrease) gradually from (to) the zero Doppler shift at the start (end) of the lacuna event. In this figure, only the 128-line amplitude spectra recorded on one antenna at around $110 \mathrm{~km}$ group range for all frequencies (i.e. 1.5 to $2.7 \mathrm{MHz}$ in $50 \mathrm{kHz}$ steps) of each CIT subset are displayed. Each single spectrum was normalized to its maximum amplitude, and the dynamic gray-scale ranged from the most probable amplitude to the maximum amplitude for each spectrum to achieve optimum signal-to-noise contrast.

Neglecting refraction effects, each relevant line in the Doppler spectra can be associated with a virtual reflection point with a line-of-sight velocity proportional to its Doppler shift. The positive and negative Doppler lines correspond to echoes approaching and receding relative to the receiving site. In a quiescent E-region, echoes are expected mainly from the zenith. The Doppler spectra should, therefore, have 

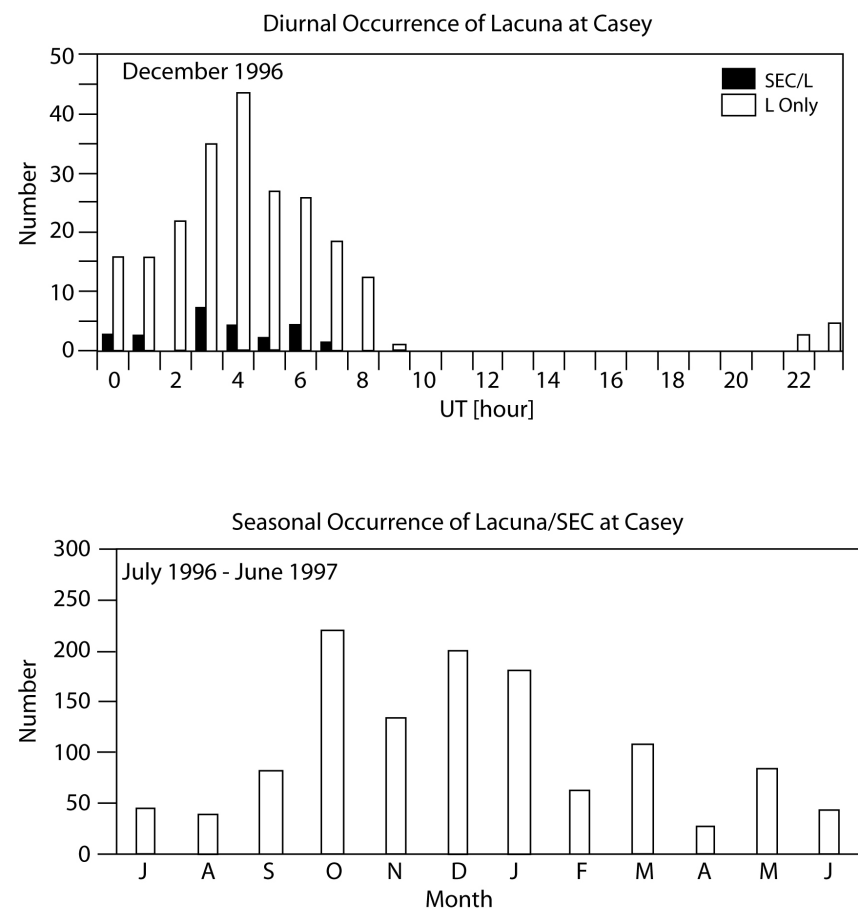

Fig. 4. Diurnal occurrence distribution for lacuna and SEC observed at Casey for December 1996 (top). Seasonal occurrence distribution for lacuna observed at Casey between July 1996 and June 1997 (bottom), where the lacuna/SEC occurrence number has been normalized to six observations per hour (i.e. corresponding to the number of ionogram soundings), and only lacuna/SEC observations during the interval 01:00-12:00 UT have been considered.

negligible overall Doppler shifts and narrow widths. Such spectra are commonly observed in Digisonde drift records, as shown in Fig. 6, before and after the lacuna condition, where the widths are $10 \%$ or less than the absolute unambiguous Doppler range (of $6.25 \mathrm{~Hz}$ for a 20 -second long CIT). The composite nature of SEC/lacuna Doppler spectra, with their symmetrically displaced spectral peaks, is characteristic of a Bragg scattering mechanism.

As the frequency increases from 1.5 to $2.7 \mathrm{MHz}$, so do the side-peak relative amplitudes with respect to the main central peaks, indicating that the effect strengthens as the radio waves penetrate deeper into the E-layer. The average side-peak Doppler shift during a single 90 -second measurement stays approximately constant over the sounding frequency range. Individual E-region drift measurements were separated by $7 \mathrm{~min}$, on average, and show variations in the Doppler spectra side-peak positions over the duration of SEC/lacuna conditions; see, for example, the spectra recorded immediately after 02:00 UT in Fig. 6.

Finally, four antenna amplitude spectra recorded at $2.35 \mathrm{MHz}$ and $100 \mathrm{~km}$ group range were overlaid in Fig. 7 . The main central peak, with a half-width less than $\pm 0.5 \mathrm{~Hz}$, is well separated from the side-peaks located between $\pm(1.56-0.78) \mathrm{Hz}$. The horizontal line at $10 \mathrm{~dB}$ indicates the most probable amplitude level for this particular spectrum.
Therefore, E-region high Doppler resolution measurements allow us to discriminate in Doppler between total reflections and scattering from irregularities. We take advantage of this discrimination when DSI was applied to the drift data. The side-peak maximum amplitudes were generally 5 to $15 \mathrm{~dB}$ lower than the central peak maximum value in the 90, 100, 110 and $120 \mathrm{~km}$ group range bins retained for post analysis over the entire sounding frequency interval, but were well above the spectra most probable amplitudes ( $\sim$ noise floor). The situation was occasionally reversed on $120 \mathrm{~km}$ group range spectra, where side-peaks could have larger amplitudes than the central peak.

\subsection{Geophysical conditions during E-region Bragg scatter events}

We now focus on a spectacular event which occurred on 30 December 1996. Figure 8 shows the Doppler signatures during three successive lacuna conditions, starting at 03:00, 03:45 and 07:45 UT, respectively. The upper plot in Fig. 8 summarizes 12 hours of E-region drift spectra gathered on a single antenna (central antenna of our four antenna array interferometer). The middle plot displays a 12-hour portion of the quiet-day curve (QDC) of a co-located $30 \mathrm{MHz}$ riometer (thick line), together with absorption values (thin line). The correspondence between riometer absorption events and the lacuna E-region spectral signature on 30 December 1996 was striking. The low-level absorption $(<0.2 \mathrm{~dB})$ during the first two hours of the day may be traced back to the F-region absorption or to weak particle precipitation. Multi-beam ionograms show, for example, the signature of polar patches moving through the radar field-of-view, at times similar to those reported by Buchau et al. (1983) and Breed et al. (2002). Note also that strong and long lasting sporadic-E events occurred between the second and third lacuna occurrences and from 08:30 UT onwards, none leading to either increased riometer absorption levels or to side-peaks in the E-region Doppler spectra. However, the sporadic-E events produced a broadening of the single central-peak corresponding to total reflections. The effect was clearly visible after 08:30 UT in the Fig. 8 upper plot when strong blanketing sporadic-E prevailed.

To complete the ensemble of observational evidence for 30 December 1996, 1-minute magnetic deviations $\Delta H$ (continuous line) and $\Delta \mathrm{D}$ (dotted line), measured by a colocated fluxgate magnetometer, are shown in the bottom panel of Fig. 8. Geomagnetic perturbations are produced by ionospheric E-region currents mainly driven by omnipresent magnetospheric convection electric fields in the polar cap and modulated by ionospheric conductivities and thermospheric neutral winds. The horizontal $\Delta \mathrm{H}$ deviation peaks correspond almost perfectly to the periods of increased riometer absorption greater than $0.25 \mathrm{~dB}$ in Fig. 8. When the magnetic declination deviation $\Delta \mathrm{D}$ (here measured positive eastwards from geographic north) stayed approximately constant and pointed toward geographic (compass) north/north-west (north-east/east) over these periods of increased magnetic 


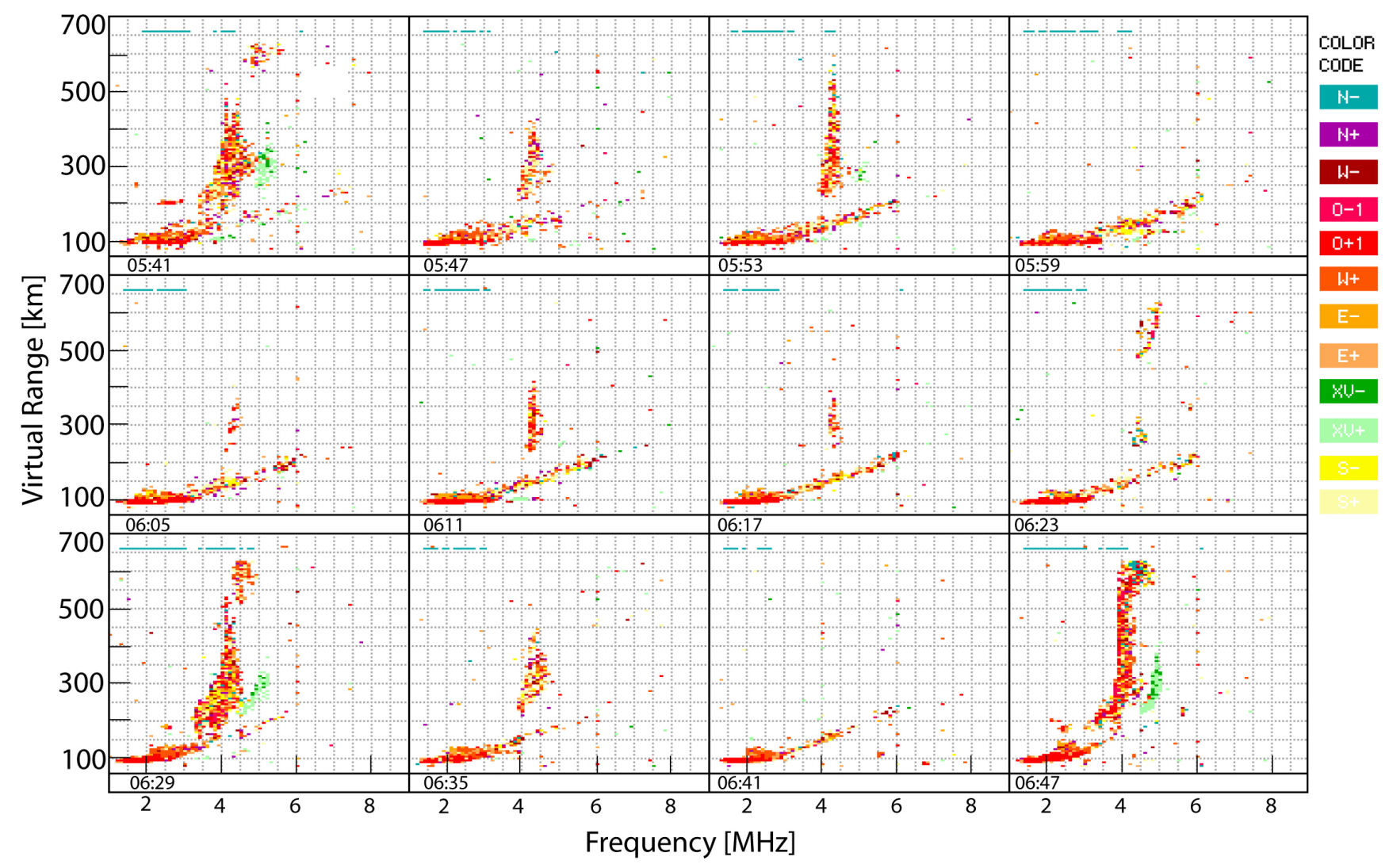

Fig. 5. Multi-beam ionogram records showing the development of a polar cap lacuna and associated slant Es conditions (SEC), starting at 05:41 UT and lasting over $1 \mathrm{~h}$ on 15 December 1994. Each ionogram ranges from 1 to $8 \mathrm{MHz}$ in $100 \mathrm{kHz}$ steps. Color-coded and optically weighted fonts provide coarse angle-of-arrival and Doppler information. All cardinal directions are expressed in a compass-oriented coordinate system. At each sounding frequency, a coherent integration of 128 phase-coded pulses at 200-Hz PRF for multiplexed O- and $\mathrm{X}$-modes is performed separately on the system four receiver antennas.

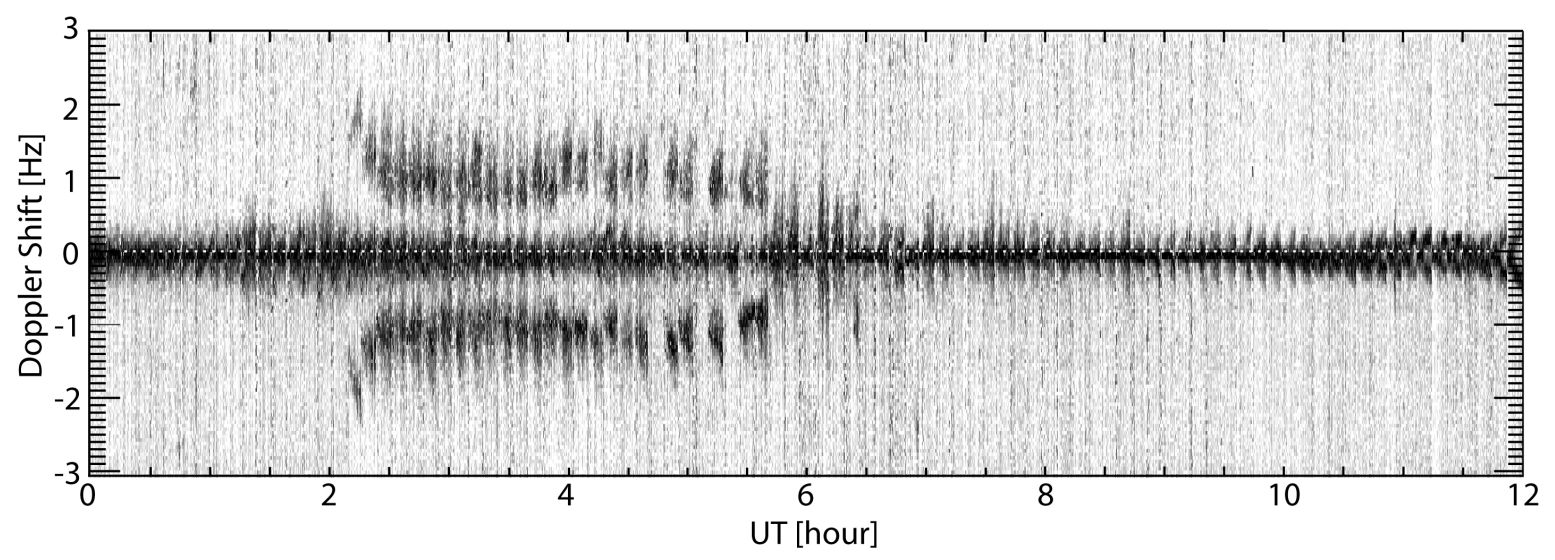

Fig. 6. E-region drift dynamic spectra recorded from 00:00 to 12:00 UT on 16 December 1996. Only the amplitude spectra recorded on one antenna and at around 110-km group range for all frequencies per CIT subset are displayed. Each single spectrum is normalized to its maximum amplitude. The dynamic gray-scale ranges from the most probable to the maximum amplitudes to achieve optimum signal-to-noise contrast. The overall Doppler range spans $6.25 \mathrm{~Hz}$. The sounding frequencies range from 1.5 to $2.65 \mathrm{MHz}$ per single measurement. The group ranges never exceed $150 \mathrm{~km}$ over the entire time interval and truly correspond to E-region Doppler drift measurements. Side-peaks appearing between 02:00 and 06:00 UT are spectral signatures observed during intense SEC/lacuna conditions. 


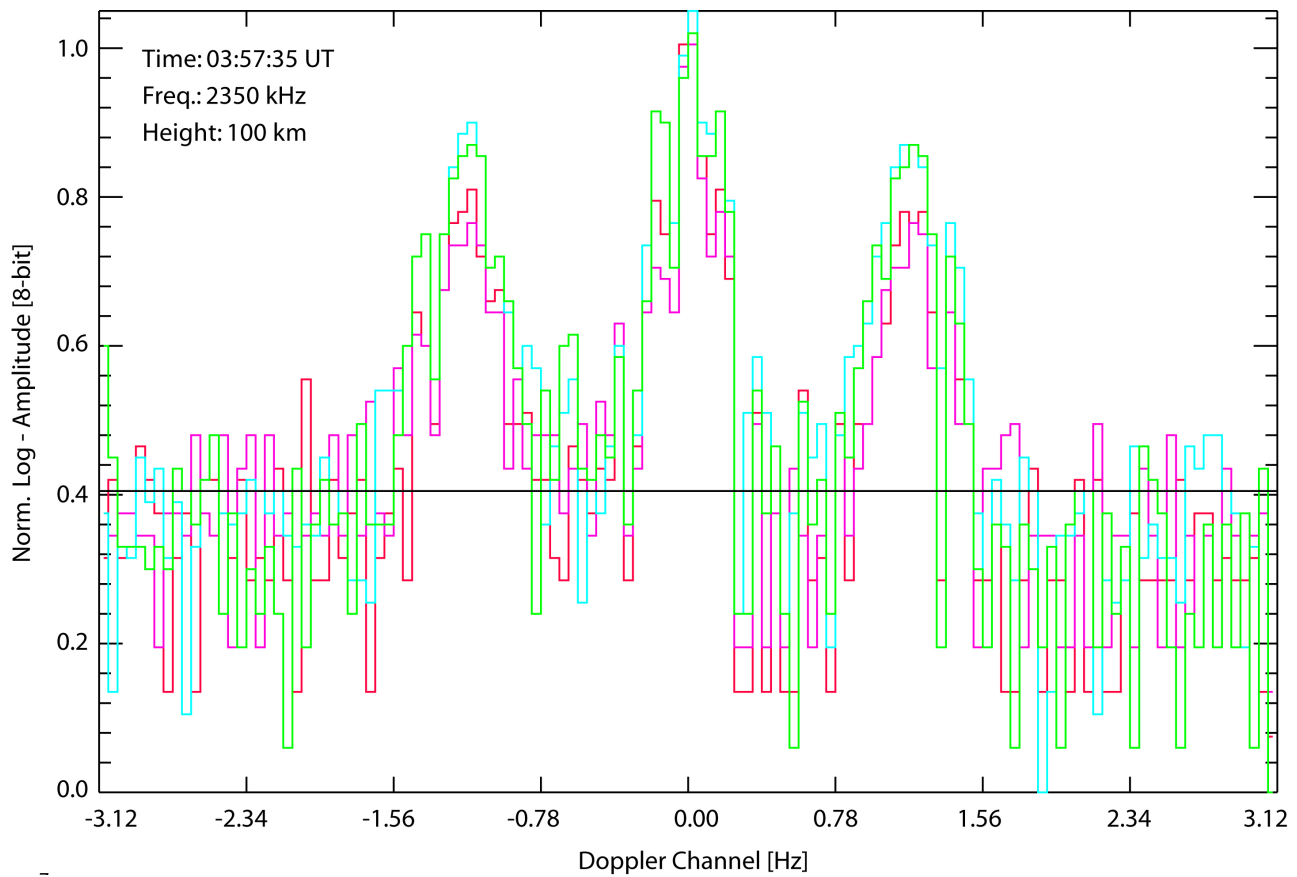

Fig. 7. Superimposed four antenna log-amplitude spectra recorded for a sounding frequency of $2.35 \mathrm{MHz}$ and $100 \mathrm{~km}$ group range recorded at 03:57 UT on 16 December 1996. The thin horizontal line at around $10 \mathrm{~dB}$ indicates the most probable amplitude. Both the side-peaks and center-peak are well above the noise floor. In this particular instance, only 3 to $4 \mathrm{~dB}$ separates Bragg backscatter from total reflection echoes.
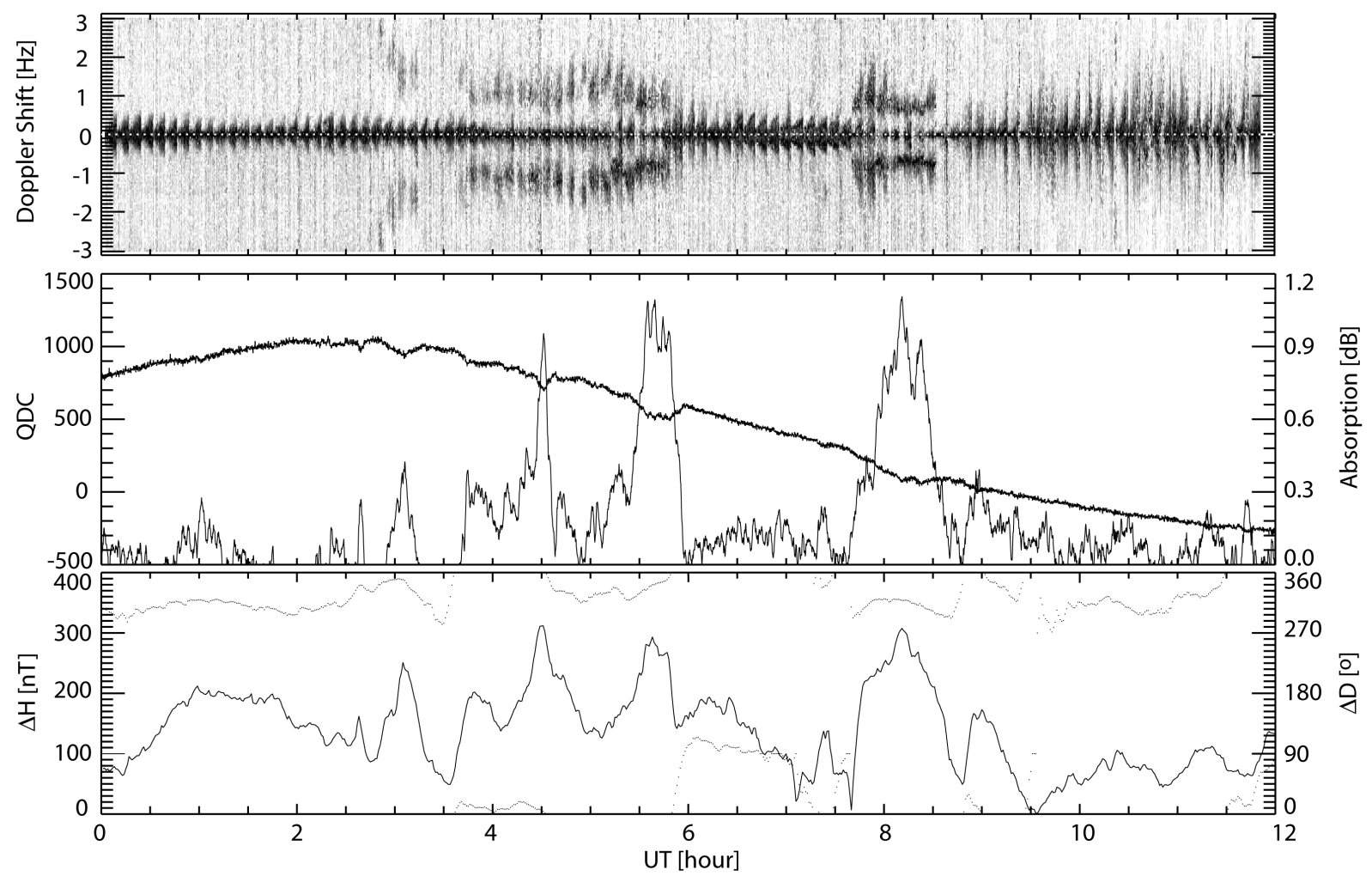

Fig. 8. E-region spectra, absorption and magnetic signatures during three successive SEC/lacuna events on 30 December 1996, starting at 03:00, 03:45 and 07:45 UT, respectively. The top window summarizes 12 hours of E-region drift spectra recorded on the central antenna of our four-antenna array interferometer. The middle window displays the corresponding quiet-day curve (QDC) of the co-located $30 \mathrm{MHz}$ riometer (thick line), together with absorption $\mathrm{dB}$ values (thin line). The bottom window shows coincident fluxgate magnetometer horizontal $\Delta \mathrm{H}$ (continuous line) and declination $\Delta \mathrm{D}$ (dotted line) components. $\Delta \mathrm{D}$ is measured positive eastwards from geographic north. 
16 December 1996

02:26:44-02:27:37 UT

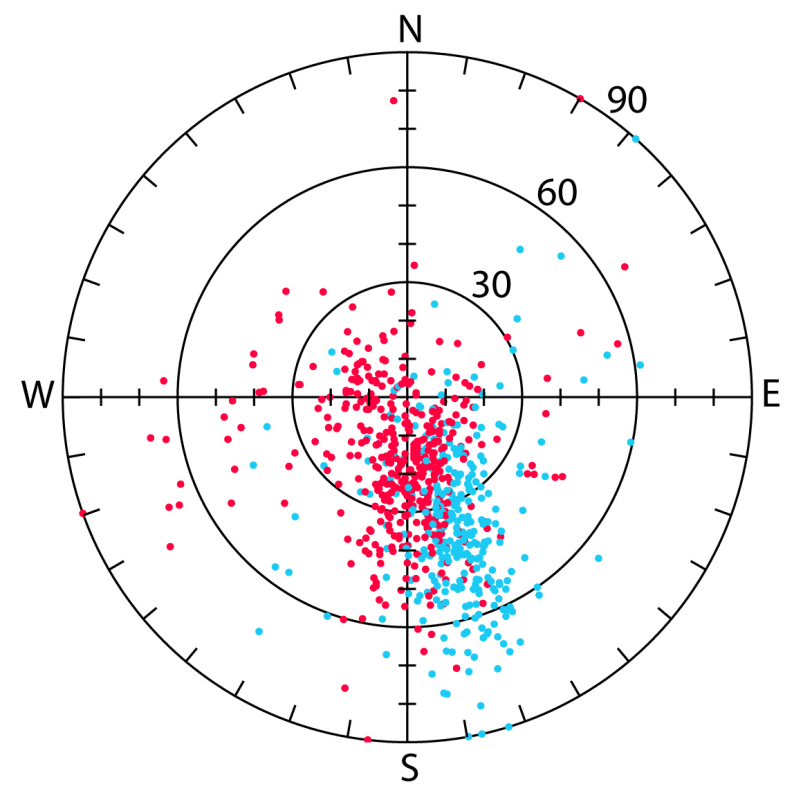

17 December 1996 02:26:44-02:27:37 UT

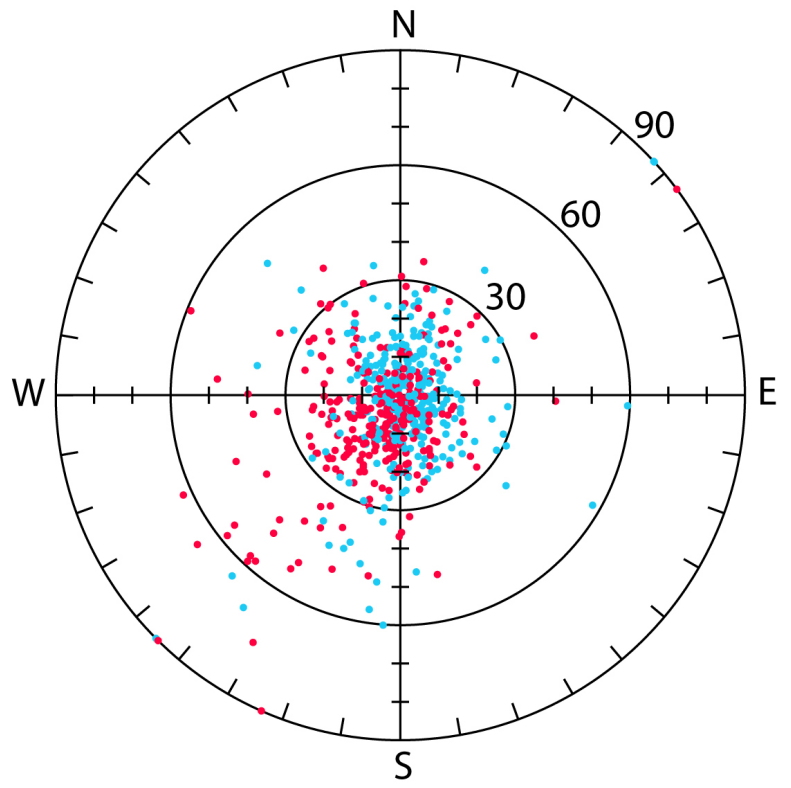

Fig. 9. Comparison between echo-location maps derived from E-region drift measurements performed on 16 and 17 December 1996 between 02:26 and 02:28 UT (approximately 10:30 LT at Casey). Approaching and receding echoes are displayed in blue and red, respectively. All cardinal directions are expressed in a compass oriented coordinate system. Concentric circles indicate zenith angles separated by $30^{\circ}$.

field strength, the lacuna, their E-region Doppler spectrum signatures and riometer absorption were coincident. The lacuna on- and off-times were marked by sharp changes in the magnetic declination and horizontal deviations, indicative of sudden changes in the E-region currents both in strength and direction.

\section{Data analysis}

\subsection{Angle-of-arrival estimation of Bragg scatter echoes}

The determination of the echo angles-of-arrival using DSI revealed further interesting features. Figure 9 compares the echo-location maps (also called sky-maps) derived from Eregion drift measurements performed on 16-17 December 1996 between 02:26 and 02:28 UT ( 10:30 LT). When lacuna was present on 16 December 1996, the echoes were spread along the compass north/north-west to south/southeast direction (Casey declination corresponds to geographic $92^{\circ}$ west) to low elevation angles (up to $60^{\circ}$ in zenith) and were mostly displaced from the zenith. Echoes with positive (blue) and negative (red) Doppler shifts were also well separated in the sky. In contrast, 17 December 1996 ionogram data and E-region drift measurements did not show any sign of lacuna at the time. The echoes were mainly confined to within a $30^{\circ}$ zenith-angle cone in the sky-map, with no obvious anisotropy in azimuth. Furthermore, echoes with positive and negative Doppler shifts were not as spatially separated and resulted in rather low overall velocities, which may ul- timately influence the azimuth measurement precision when velocities are derived by a least-squares fit procedure.

The compass north-south and east-west range distributions as functions of the Doppler shift, shown in Fig. 10, were constructed from 12581 and 10280 sky sources, observed, respectively, between 02:05 and 04:10 UT on the 16 December 1996 (top row) and 17 December 1996 (bottom row). The sources were distributed in $10 \mathrm{~km}$ by $0.1-\mathrm{Hz}$ Dopplerrange bins. The distributions were further smoothed with a running average $3 \times 3$-element window. The distributions for the 16 December 1996 were sharply centered around $50 \mathrm{~km}$ south and $10 \mathrm{~km}$ east at $0 \mathrm{~Hz}$ Doppler. They also exhibit two secondary maxima located around $30 \mathrm{~km}$ south and $5 \mathrm{~km}$ west, and $70 \mathrm{~km}$ south and $25 \mathrm{~km}$ east, at -1.0 and $+1.0 \mathrm{~Hz}$ Doppler respectively. These secondary maxima correspond one-on-one to the side-peaks in the spectra shown in Fig. 6. For all three peaks, most sources were confined within small windows of comparable widths in horizontal range $(<100 \mathrm{~km})$ and Doppler $(<1.0 \mathrm{~Hz})$ and did not overlap. In contrast, sources recorded on 17 December 1996 were narrowly distributed in range with a peak centered around $15 \mathrm{~km}$ south, with no appreciable zonal deviation at zero Doppler, and the distributions did not show secondary maxima at larger Doppler shifts. On both days, the east-west distribution half-widths span $15 \mathrm{~km}$ compared to $30 \mathrm{~km}$ for the north-south direction.

Simple trigonometry applied to the north-south and eastwest distribution maxima for an estimated $95-\mathrm{km}$ reflection true height showed that negative, zero and positive Doppler 

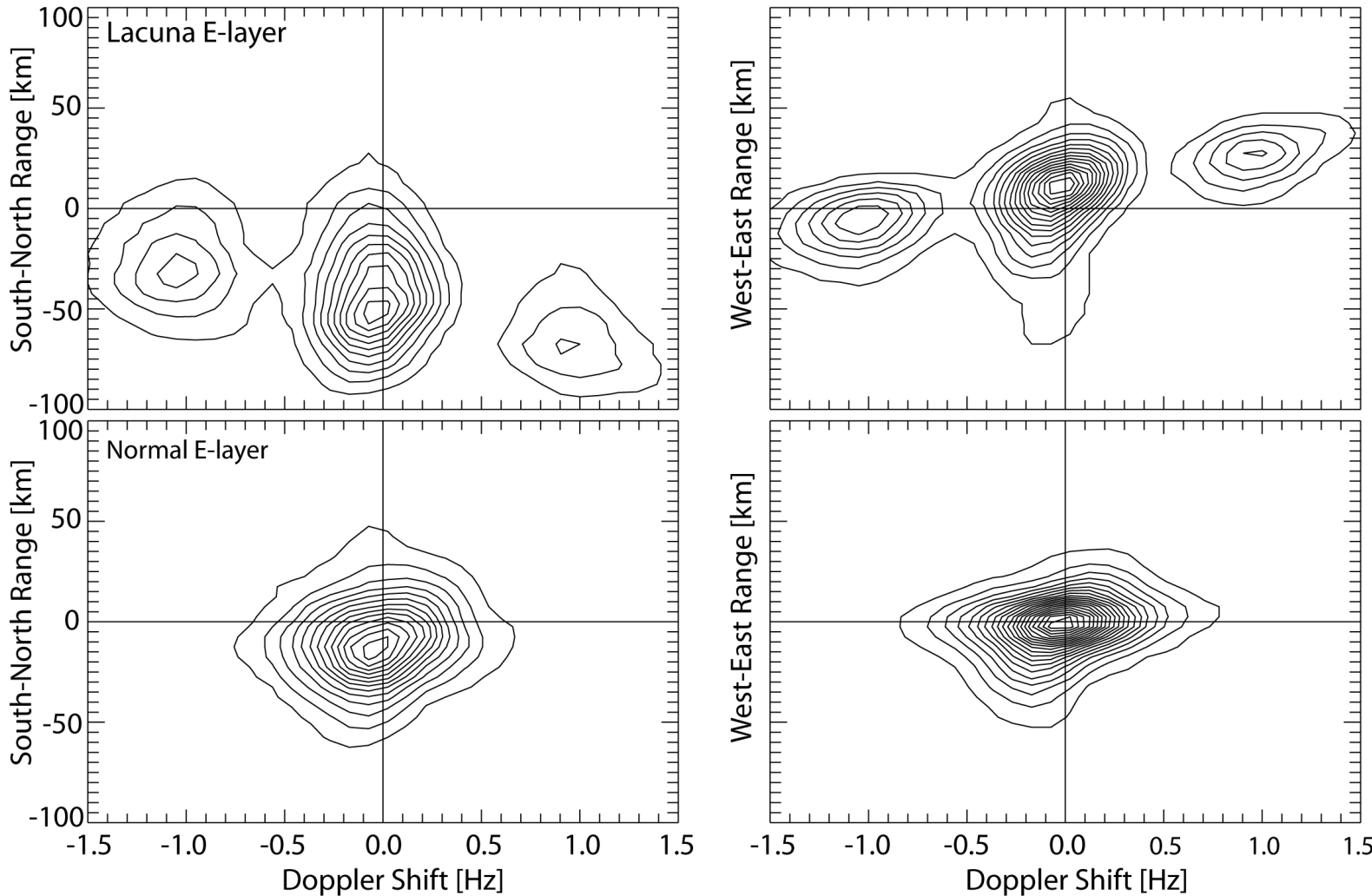

Fig. 10. Comparison between compass north-south and east-west range echo-location distributions as a function of Doppler shift observed between 02:05 and 04:10 UT on 16 (top) and 17 (bottom) December 1996 (constructed from 12581 and 10280 sky sources, respectively), and distributed in $10-\mathrm{km}$ by $0.1-\mathrm{Hz}$ Doppler-range bins.

echoes approximately originated on 16 December 1996 from the following zenith and compass azimuth sets: $\left(18^{\circ}, 189^{\circ}\right)$, $\left(28^{\circ}, 169^{\circ}\right)$ and $\left(38^{\circ}, 160^{\circ}\right)$. The sets, respectively, corresponded to the east-west/north-south locations $(-5,-30)$, $(10,-50)$ and $(25,-70)$ measured in kilometers on the sky-map and were aligned along the compass directions $323^{\circ} / 143^{\circ}$. It appears that both the total and backscatter reflection surfaces between 90 and $120 \mathrm{~km}$ group ranges were severely tilted during the lacuna condition prevailing on 16 December 1996. We note that comparable tilts were also measured for the events recorded on 30 December 1996. On 17 December 1996, the distribution maxima for zero Doppler echoes corresponded to $9^{\circ}$ zenith and $180^{\circ}$ compass azimuth angles.

\subsection{Ray-tracing simulation}

The ray-tracing simulation results are presented in Fig. 11, where ordinary polarized rays at $2 \mathrm{MHz}$ were traced through a horizontal Chapman alpha-layer parameterized by a peak height, critical frequency and scale height values of $105 \mathrm{~km}$, $4 \mathrm{MHz}$ and $7 \mathrm{~km}$, respectively. This particular choice of parameters was dictated by our range of sounding frequencies, the E-region maximum frequency observed on ionograms recorded during the E/F-lacuna conditions, shown in Fig. 3 with $\left(\mathrm{f}_{o} \mathrm{E}>3.5 \mathrm{MHz}\right)$, as well as the generally accepted values for the E-region peak and scale heights. Reflection occurs when the refractive index, $\mathrm{n}$, tends to zero where $\mathrm{n}=\{1-X\}^{1 / 2}$. The true heights, magneto-ionic $X\left(=f_{\text {plasma }}^{2} / f_{\text {radar }}^{2}\right)$ parameters and magnetic aspect angles $\left(=\sin ^{-1}\{\boldsymbol{B} \cdot \boldsymbol{k} /|\boldsymbol{B} \| \boldsymbol{k}|\}\right)$ were computed along the rays for take-off zenith and azimuth angles that ranged from $0^{\circ}$ to $50^{\circ}$ in $5^{\circ}$ steps and from $0^{\circ}$ to $315^{\circ}$ in $45^{\circ}$ steps, respectively. The true height trajectories displayed in the Fig. 11 (top plot) indicated that both total and backscatter echoes returned from a narrow true height interval between 91 and $93 \mathrm{~km}$ for zenith angles that ranged from $0^{\circ}$ to $50^{\circ}$. The band structure particularly visible on the magneto-ionic $X$ and aspect angle plots was caused by effects of the three-dimensional International Geomagnetic Reference Field (IGRF) model included in the simulation. Each band of rays corresponded to a fixed elevation but different azimuth angles.

Favourable backscatter conditions were met for all azimuths, as the aspect angle zero line intercepted all curves on the bottom plot of Fig. 11. For a given group range interval, favourable backscatter take-off angles were correspondingly restricted as the perpendicularity condition was achieved monotonically at increasing ranges for increasing take-off angles. Neither total reflection nor backscatter echoes were 


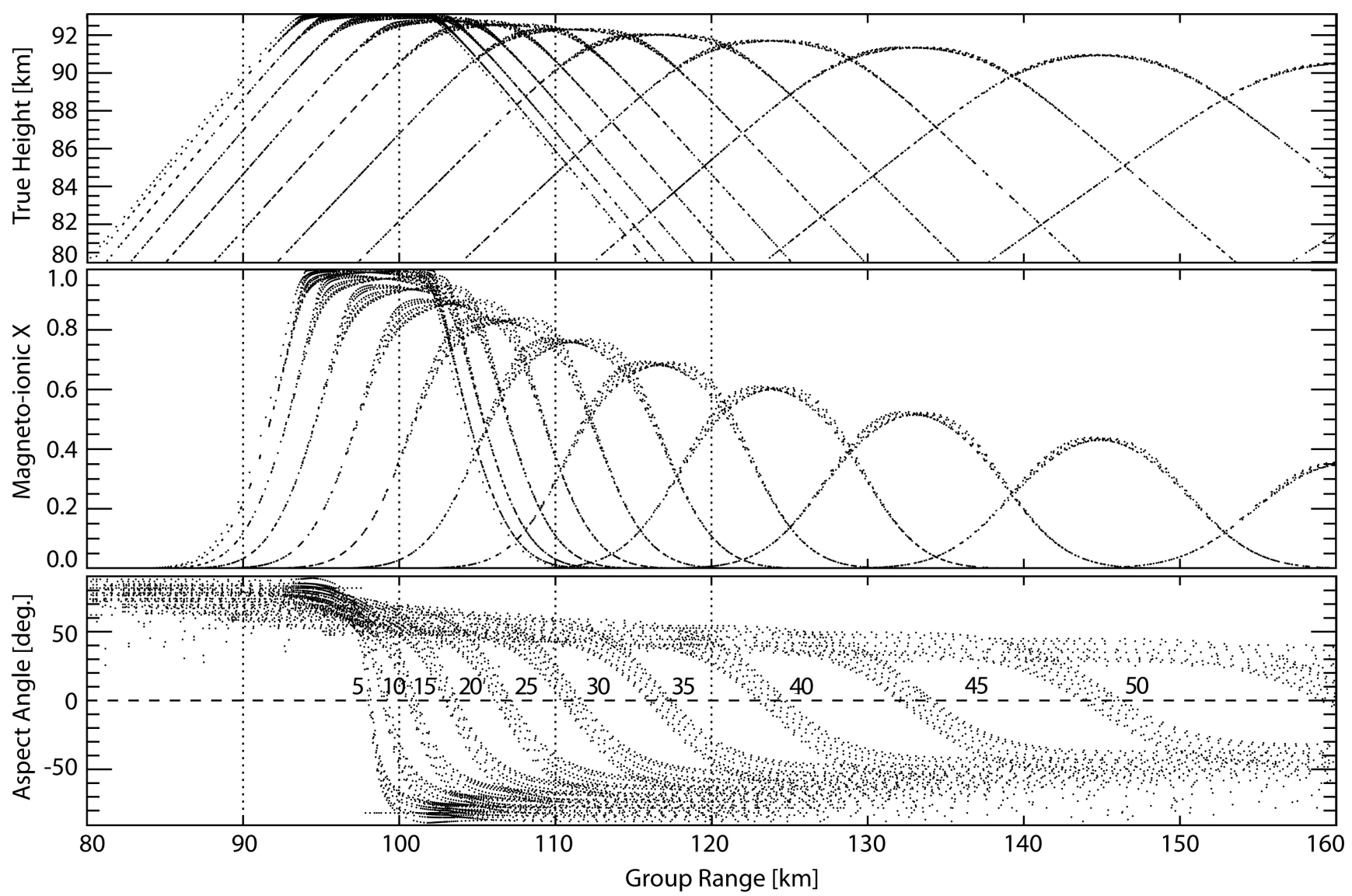

Fig. 11. Results of three-dimensional ray tracing through a Chapman E-layer for a sounding frequency of $2 \mathrm{MHz}$ at Casey station. The layer is parameterized by a peak height, critical frequency and scale height values of $105 \mathrm{~km}, 4 \mathrm{MHz}$ and $7 \mathrm{~km}$, respectively. The geomagnetic field, IGRF 2000, has been included in the simulation. The ray true heights, magneto-ionic $X$ parameters and magnetic-aspect angles are plotted against the group ranges for zenith angles ranging from $5^{\circ}$ to $55^{\circ}$ in $5^{\circ}$ steps.

expected at $2 \mathrm{MHz}$ from the $10 \mathrm{~km}$ wide group range bin centered at $90 \mathrm{~km}$ (the Digisonde nominal pulse width after compression equaled $10 \mathrm{~km}$ ). Specular and oblique echoes due to total reflection processes may be expected within the 100$\mathrm{km}$ group range bin for zenith angles between $0^{\circ}$ and $13^{\circ}$, where the magneto-ionic $X$ parameter remained above 0.95 . Backscatter was possible for zenith angles that spanned $13^{\circ}$ to $23^{\circ}, X$ ranged from 0.95 to 0.85 . For the last two 110 and $120 \mathrm{~km}$ group range bins, only backscatter echoes coming from $23^{\circ}$ to $40^{\circ}$ zenith angles could be achieved with $X$ below 0.85 . Although the simulation did not take into account the measured tilts, the electron density fluctuations associated with E-region irregularities and the Digisonde imperfections, it indicated that backscatter echoes could be expected at large zenith angles, and were returned from altitudes close to the cutoff that corresponded to $X=1$. The refraction experienced by the Digisonde low-frequency HF waves in the 90 to $95 \mathrm{~km}$ range implied that irregularity Doppler shifts should be approximately constant and independent of zenith angles at fixed sounding frequencies and thus explained the composite nature of the E-region SEC/lacuna spectra.

\subsection{Estimation of apparent velocities of Doppler spectra central and side-peaks}

The spatial and Doppler separations of sky-map sources presented in Fig. 9 lead us to estimate the apparent ionospheric velocities $V_{\mathrm{DDA}}$ for central and side-peaks in the Doppler spectra separately for all E-region drift spectra recorded between 02:05 and 06:00 UT on 16 December 1996. We also neglected refraction and assumed overall uniform phase and bulk velocities for both the E-region irregularities and the underlying bulk-motion. Figure 12 shows the vertical and horizontal velocity and azimuth angle distributions using: 1) all relevant Doppler spectra lines (top row), 2) only the Doppler spectra center-peak lines between $\pm 0.781 \mathrm{~Hz}$ (middle row), and 3) only the Doppler spectra side-peak lines between $\pm(0.781-3.125) \mathrm{Hz}$ (bottom row). The vertical and horizontal velocity and azimuth angle distributions corresponded to all lines (center-peak and side-peak) in the Doppler spectra, maximized at $5 \mathrm{~ms}^{-1}, 187.5 \mathrm{~ms}^{-1}$ and $307.5^{\circ}$, respectively (compared with the rough estimates directly deduced from the echo distributions computed 

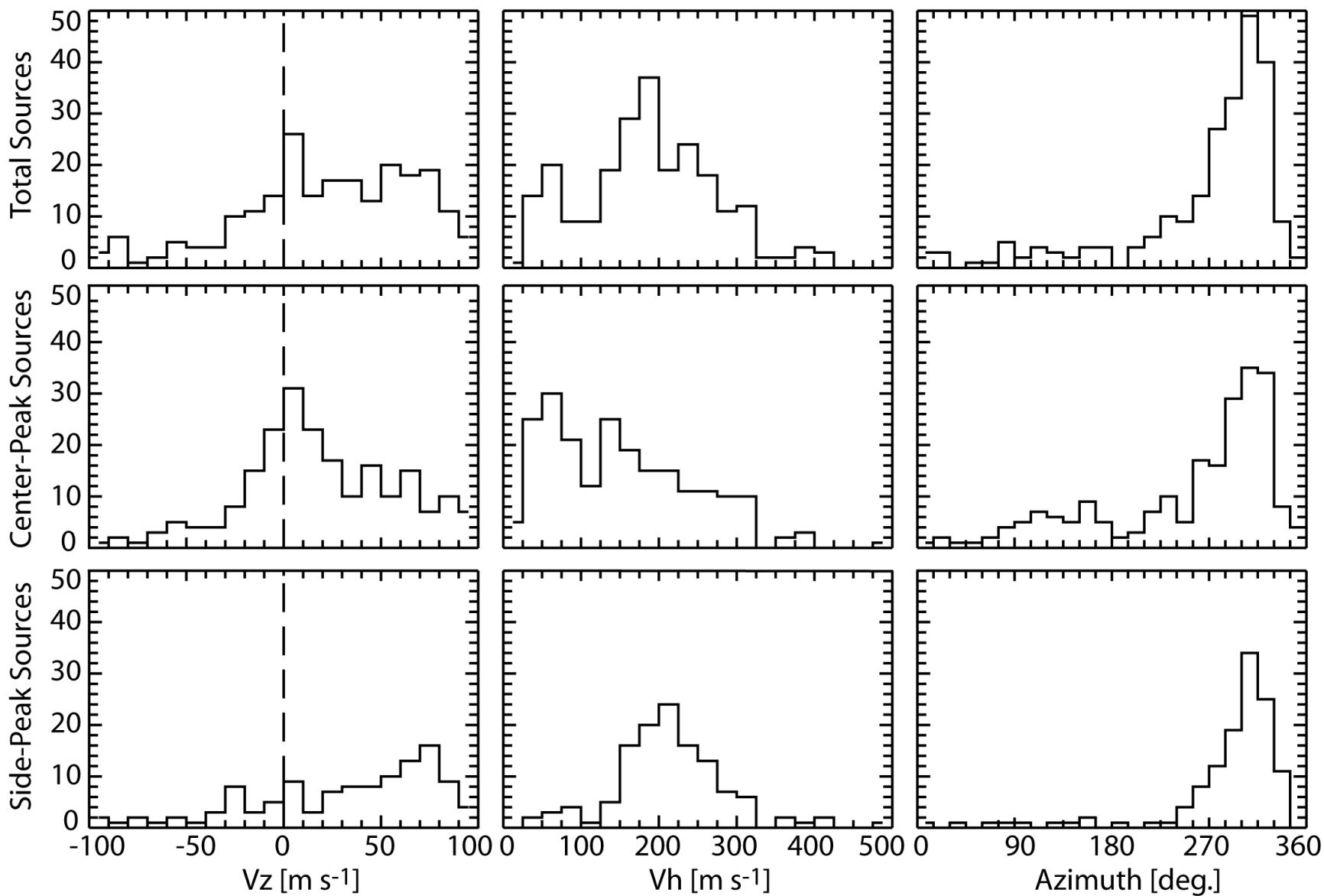

Fig. 12. Occurrence histograms of vertical velocity $\left(\mathrm{V}_{z}\right)$, horizontal velocity $\left(\mathrm{V}_{h}\right)$, and azimuth angle used for computations: (top row) all Doppler spectral lines between $\pm 3.125 \mathrm{~Hz}$; (middle row) only Doppler spectral center-peak lines between $\pm 0.781 \mathrm{~Hz}$; and (bottom row) only Doppler spectra side-peak lines between \pm 0.781 and $\pm 3.125 \mathrm{~Hz}$. For all cases, we assumed that the E-region undergoes uniform bulk motion. The velocity components are expressed in a compass oriented coordinate system.

above). All azimuths were measured positive eastwards from compass north. The distributions were rather broad, with horizontal velocities reaching up to $400 \mathrm{~ms}^{-1}$ and higher at times. When only sources associated with the Doppler spectra center-peak (side-peak) lines were considered, the corresponding distribution maxima reached $5 \mathrm{~ms}^{-1}, 62.5 \mathrm{~ms}^{-1}$ and $307.5^{\circ}\left(75 \mathrm{~ms}^{-1}, 212.5 \mathrm{~ms}^{-1}\right.$ and $\left.307.5^{\circ}\right)$. The inclusion of sources associated with Bragg backscatter from E-region irregularities had the effect of increasing the horizontal component of the E-region drift velocity by a factor of three and skewing the vertical velocity distribution toward positive values (compare top and middle rows in Fig. 12). Thus, the indiscriminate application of DSI to the entire E-region spectra would clearly overestimate the E-region background drift velocities during SEC/lacuna conditions.

\subsection{Estimation of apparent velocities of Doppler spectra side-peaks for $\mathrm{n}<1$}

At low HF frequencies ionospheric refraction is important, particularly at high-latitudes where the geomagnetic field is almost vertical, and where refraction effects allow the or- thogonality condition to exist, which is essential for the detection of Bragg scatter echoes. The Bragg scatter or irregularity apparent velocity amplitude $V_{\mathrm{DDA}}$ obtained above does not include refraction effects. The estimated vertical and horizontal velocities were obtained from the direct application of Pfister's theorem which simply relates the echo angle-of-arrival (AOA), Doppler shift and velocity of the reflection point, viz., $\boldsymbol{k}_{0} \boldsymbol{V}_{D D A}=\pi \Delta f$ (Pfister, 1971; Bennett and Dyson, 1993). The UMLCAR Digisonde Drift Analysis package used for the computations assumed that the refractive index $n=1$ at the scatter center or equivalently that the radar wave vector remained equal to its free space value $\boldsymbol{k}_{0}$ along the radio-wave path. Disregarding collisions and the geomagnetic field, the refractive index is approximately equal to $\{1-X\}^{1 / 2}$. From the simulation results presented in Fig. 11, we estimated that $X \leq 0.75$ and $0.5 \leq n \leq 1.0$ for $2 \mathrm{MHz}$ oblique echoes with zenith angles $\leq 30^{\circ}$. The irregularity velocities $\boldsymbol{V}_{i}$ derived directly from the general form of Pfisters' theorem (Bennett and Dyson, 1993), $\boldsymbol{k} \cdot \boldsymbol{V}_{i}=\pi \Delta f$ (where $\boldsymbol{k} \cong n \boldsymbol{k}_{0}$ is the radar wave vector at the scatter center and $\Delta f$ is the measured Doppler frequency shift), were clearly underestimated by $\boldsymbol{V}_{D D A}\left(\cong n \boldsymbol{V}_{i}\right)$. If one assumes 
that the aspect angle is nearly zero at the scatter center, then the measured Doppler shift is directly proportional to the irregularity velocity amplitude $V_{i}$ (with $\boldsymbol{k}$ and $\boldsymbol{V}_{i}$ being almost aligned). For mean spectral signatures of $\pm 1.0 \mathrm{~Hz}$ at $2 \mathrm{MHz}$ and echoes coming from $30^{\circ}$ zenith angles $(X=0.75$ and $n=0.5$ at $110 \mathrm{~km}$ group range), we found $V_{i} \cong 425 \mathrm{~ms}^{-1}$ (for the DDA computed $\mathrm{V}_{\mathrm{h}}=212.5 \mathrm{~ms}^{-1}$ that corresponded only to the side-peaks in the Doppler spectra, as shown in the bottom row of Fig. 12).

\section{Discussion}

For ordinary mode HF radio waves, Bragg backscatter occurs when the radio-wave vectors are approximately at right angles with respect to the local magnetic field and the fieldaligned irregularity wavelengths equal half the incident radio wavelength at the backscatter center. Given the ionospheric refraction at low HF frequencies and the large magnetic dip angle at polar cap latitudes $\left(-81^{\circ}\right.$ at Casey), the perpendicularity condition is generally met for a wide range of elevation, and all azimuth angles and backscatter reflections occur at increasing ranges for increasing frequencies.

When HF radio waves are reflected by the ionosphere, the characteristics of time-varying disturbances embedded within the reflecting region are imposed on the scattered signal spectral components. Over-the-horizon radar backscatter Doppler spectra of radio waves reflected from the sea surface show a striking resemblance to those presented in this paper (Earl and Ward, 1986) and were explained in terms of multiple Bragg-resonant scattering (Skolnik, 1990). Tsunoda et al. (1997) recorded similar spectra with the continuouswave 12.3-MHz radar HF-OSCAR (Olesen et al., 1983) located at Søndre Strømfjord in Greenland. These authors concluded that the spectra were produced by the modified two-stream instability, given their narrow spectral widths and peak Doppler velocities comparable to the ion-acoustic speed at around $95-\mathrm{km}$ altitude.

Interestingly, the Doppler shifts or line-of-sight velocities of so-called "chaotic" Es-echoes, recorded by Wright and Argo (1994) at Troms $\varnothing$ with a Dynasonde, showed similar trends for sounding frequencies from 1 to $3 \mathrm{MHz}$, although their line-of-sight velocities did not display symmetrically displaced side-peaks. They estimated that half of the decibel difference between total and backscatter echo amplitudes was due to the echo oblique paths and was specific to their own transmit and receive systems. However, Wright and Argo (1994) concluded that these chaotic echoes were probably caused by near total reflections, rather than under-dense Bragg scattering.

Like its equatorial counterparts, the diffuse SEC echoes observed on high-latitude ionograms have been explained in terms of oblique radio-wave Bragg backscatter from Eregion field-aligned irregularities (Cohen et al., 1962; Olesen et al., 1983; Olesen et al., 1986). We have demonstrated that SEC traces appear on ionograms at the end of the normal Eregion layer from $3 \mathrm{MHz}$ at $110 \mathrm{~km}$ for typical high-latitude mid-summer days around local noon and extend steadily upwards with increasing frequencies (up to $6 \mathrm{MHz}$ and $230 \mathrm{~km}$ group range in Fig. 5).

Stauning (1998) reviewed radio-wave absorption events in the dayside polar cap boundary region and identified up to ten distinct event-types and associated characteristics commonly observed with $30-\mathrm{MHz}$ riometers located at these latitudes. Given Casey's location within the polar cap or under the polar cusp ( $80.8^{\circ} \mathrm{S}$ CGM), enhanced electron collision frequencies caused by anomalous electron heating of the E-region by unstable plasma waves driven by high electric fields are the most likely candidates causing the riometer signatures observed during the December 1996 summer campaign, as shown in Fig 8 (Schlegel and St.-Maurice, 1981). They explain the absorption level, event duration and local time occurrences.

The close association between the reported E-region Bragg scatter sources or possible irregularities, and enhancements in the geomagnetic horizontal component $\Delta \mathrm{H}$ (Fig. 8) was also observed at equatorial latitudes. In a fundamental publication on the nature of equatorial slant sporadic E, Cohen et al. (1962) showed that the development of the condition correlates with intensifications of the electrojet current measured by $\Delta \mathrm{H}$ at Huancayo, Peru. They estimated the east-west coherence of the current variations along the magnetic equator to extend over at least $500 \mathrm{~km}$, as deduced from E-region slant-echo ranges. Similarly, SEC/lacuna conditions at polar latitudes appear to be associated with E-region current intensifications induced by convection electric fields, the coherence of convection-driven current variations extending over comparable horizontal ranges.

It is evident that reported Bragg backscatter echoes originate from below the E-region critical frequency, given the simultaneous observation on the Doppler spectra with the center-peak corresponding to total reflections. The angle-ofarrival analysis (Fig. 9 and Fig. 10) and ray-tracing simulations (Fig. 11) reveal that they are in fact oblique echoes reflected from the E-region ionosphere south of the station below the sounding frequency total reflection height. In their work on the structure of slant Es recorded at Halley Bay, Rodger and Pinnock (1986) reported a similar finding for sounding frequencies above the E-region critical frequency and echoes within the slant Es-trace.

During our campaign, for frequencies below $3 \mathrm{MHz}$, the SEC echoes could not be readily resolved on multi-beam ionograms from the normal E-region total reflections, since they had comparable group ranges (i.e. compared with the event shown in Fig. 5). It is important to remember that only the maximum amplitude line per complex spectra was kept to form the beam after digital signal processing. However, high Doppler E-region drift measurements conducted at maximum sensitivity and at frequencies below the Eregion critical frequency provided a suitable alternative for the routine monitoring of E-region processes at HF. They enabled us to differentiate between Bragg backscatter and total reflections, according to their Doppler signatures, since the entire spectra were kept for post processing. Thus, 
the indiscriminate application of DSI to the entire E-region spectra would clearly overestimate the E-region background drift speed during SEC/lacuna conditions when Bragg spectral bands appear (Fig. 12).

We suggest that the spectral symmetry observed during Bragg scatter events is the combined result of ionospheric refraction and the spatial integration over the receiver antenna beam of backscattered echoes arising from E-region irregularities at fixed group ranges. The simultaneous observation of SEC/lacuna (Fig. 3) with ionospheric absorption and magnetic field disturbances during intervals with E-region Bragg spectral bands (Fig. 8) provides further evidence for our interpretation, as confirmed in previous studies (Tsunoda et al., 1976; Stauning, 1984; Stauning et al., 1985; Olesen et al., 1986; Rodger and Pinnock, 1986). In the following, we suggest as an initial explanation that the SEC/lacuna spectra side-peaks might also represent the spectral signatures of Eregion irregularities, possibly attributed to unstable plasma waves.

\section{Preliminary interpretation of observations}

We interpret the velocities, derived from the side-peaks of the E-region Doppler spectra, as E-region irregularity phase velocities triggered primarily by two-stream instabilities (Farley, 1963; Buneman, 1963), that are possibly influenced by gradient-drift instabilities (Maeda et al., 1963). Our interpretation is largely based on previous works discussing SEC/lacuna events, rather than flow and aspect angle characteristics directly obtained from Doppler spectra through DSI (Tsunoda et al., 1976; Stauning, 1984; Stauning et al., 1985; Olesen et al., 1986; Providakes et al., 1988; Haldoupis et al., 1993). Refraction at low HF, due to both the electron density gradient and the geomagnetic field, is a major impediment to the proper determination of both aspect and flow angles, as up-going ordinary (extraordinary) radar waves are deviated horizontally and laterally towards the south magnetic pole (equator). The simultaneous observations of low-level absorption in riometer records and associated E-region current intensifications (Fig. 8) suggest plasma heating events caused by the dissipation of unstable two-stream waves, as explained by Schlegel and St.-Maurice (1981) and St.Maurice et al. (1981).

The averaged velocities $V_{i}$, estimated in Sect. 4.4, are approximately anti-parallel to the current directions derived from magnetometer records, as expected by linear theory. The $V_{i}$ estimates, clustered around $425 \mathrm{~ms}^{-1}$ when refraction was taken into account, are comparable to the ionacoustic speed $\mathrm{C}_{s}$ values expected in the bottom-side Eregion at around $95 \mathrm{~km}$. We also note that the side-peak mean Doppler shifts do not smoothly converge or diverge from the zero Doppler line, but jump at the start of the events to a finite value, approximately maintained over the SEC/lacuna event duration, before suddenly disappearing. This behaviour tends to indicate that the convection electric field, driving the instability, has reached the appropriate stabilising or destabilising threshold values.

It is commonly accepted that gradient-drift waves are less likely to be excited in the bottom E-region around local noon at polar cap or polar cusp latitudes, given that the electron density gradient (practically parallel to $\boldsymbol{B}$ ) and the convection electric field (perpendicular to $\boldsymbol{B}$ ) are nearly perpendicular to each other (Hanuise, 1983; Keskinen and Ossakow, 1983). Since particle precipitation was low during the considered intervals, it is unlikely that favourable horizontal gradients were present over Casey. However, gradient-drift processes cannot be ruled out, as large apparent tilts $\left(\sim 28^{\circ}\right)$ were measured to the magnetic south of the station during both events on 16 and 30 December 1996. They lead to destabilizing electron density gradients along the convection electric field direction, and could have lowered the two-stream drift velocity threshold below $\mathrm{C}_{s}$ (see Janhunen (1995) for a pictorial representation of this effect).

We recognize the tentative nature of our explanation, since the observation at these frequencies of such well-defined Bragg scatter from the E-region is surprising. It is worth pointing out that similar Bragg spectral bands were recently observed using an MF radar operating at $1.94 \mathrm{MHz}$ at Davis, Antarctica $\left(78.0^{\circ} \mathrm{E}, 68.6^{\circ} \mathrm{S}\right.$ geographic, $74.6^{\circ} \mathrm{S}$ magnetic) during 2001 and 2003 (Morris et al., 2003) - having similar characteristics to the events reported in this paper. We also note that the location of both Casey and Davis beneath the polar cusp around local magnetic noon varies as a function of solar cycle, dipole tilt and level of magnetic activity. Thus, particles including ionic atoms and molecules (i.e. $\mathrm{O}^{+}$and $\mathrm{NO}^{+}$) can gain direct entry through the polar cusp to the E-region that could also contribute to the generation mechanism for E-region ionospheric irregularities. Although we speculate on one possible physical interpretation for these novel E-region Bragg scatter spectral band events, presented in this paper, more observations are needed before their characteristics, morphology, source region and generation mechanism is fully understood.

\section{Conclusions}

Using multi-parameter information provided by a Digisonde located at the polar cap/cusp station Casey, Antarctica, it is possible to discriminate at low HF frequencies between Bragg backscatter and total reflection processes taking place at E-region heights during intense SEC/lacuna conditions. A summary of the paper's key points follows:

1. Digisonde measurements of drift velocity height profiles show that the occurrence of lacuna prevents the determination of F-region drift velocities, and also affects E-region drift velocity measurements.

2. We have demonstrated that a Digisonde recorded unique spectral signatures with two side-peaks corresponding to Bragg scatter at approximately $\pm 1-2 \mathrm{~Hz}$, symmetrically located on each side of a center-peak 
corresponding to near-zenith total reflections from Eregion Doppler drift measurements.

3. That Bragg backscatter events manifest during polar lacuna conditions, and affect the determination of Eregion background drift velocities, and as such must be considered when using standard Doppler-sorted interferometry (DSI) techniques to estimate ionospheric Eregion drift velocities.

4. The mutual consistency between the sudden apparition of Bragg scatter side-peaks in E-region Doppler spectra, the observed ionosphere absorption values, event duration, and the magnetic field disturbances occurring during SEC/lacuna ionosphere conditions suggest a common E-region source region and generation mechanism for this phenomenon.

5. Angle-of-arrival information and ray-tracing simulations show that echo returns are coming from oblique directions most likely resulting from direct backscatter from just below the total reflection height for each sounding frequency.

6. Given the Doppler and spatial separations of Bragg backscatter from specular reflection echoes, we estimated the irregularity phase velocity $V_{i} \sim 425 \mathrm{~ms}^{-1}$ when refraction was taken into account. This value is comparable to the ion-acoustic speed Cs expected in the bottom-side E-region.

Finally, we suggest that the reported Bragg scatter events may be related to E-region irregularities generated by plasma instability processes. And the Bragg scatter irregularity phase velocities may provide an alternative measurement of $\boldsymbol{E} \times \boldsymbol{B}$ drift when severe SEC/lacuna conditions prevent the determination of F-region drift velocities. Further research is required to unravel the Bragg scatter source region and generation mechanism in order to further develop a theoretical understanding of this interesting high-latitude E-region phenomenon.

Acknowledgements. The Australian Research Council and the Australian Antarctic Science Advisory Committee supported the installation and operation of the DPS-4 Digisonde at Casey station, Antarctica. Finally, we thank all Australian National Antarctic Research Expeditions (ANARE) members who contributed to the project, especially Drs. Anthony Breed and Darryn Schneider who ran the 1996-1997 summer drift campaign on our behalf.

Topical Editor M. Lester thanks C. J. Davis for his help in evaluating this paper.

\section{References}

Bennett, J. A. and Dyson, P. L.: On Pfister's theorem and its generalization, J. Atmos. Terr. Phys., 55, 1307-1310, 1993.

Bowles, K. L., Cohen, R., Ochs, G. R., and Balsley, B. B.: Radar echoes from field-aligned ionization above the magnetic equator and their resemblance to auroral echoes, J. Geophys. Res., 65, 1853-1855, 1960.
Breed, A. M., Dyson, P. L., and Morris, R. J.: Structure and dynamics of polar patches above Casey, Antarctica, Adv. Space Res., 30(11), 2551-2556, 2002.

Buchau, J., Reinisch, B. W., Weber, E. J., and Moore, J. G.: Structure and dynamics of the winter polar cap F region, Radio Sci., 18, 995-1010, 1983.

Buneman, O.: Excitation of field aligned sound-waves by electron streams, Phys. Rev. Lett., 10, 285-287, 1963.

Cartron, S. and Vila, P.: Polar lacuna on ionograms: I. Brief morphology, Ann. Geophys., 12, 355-358, 1994.

Cohen, R., Bowles, K. L., and Calvert, W.: On the nature of equatorial slant sporadic E, J. Geophys. Res., 67, 965-972, 1962.

Earl, G. F. and Ward, B. D.: Frequency management support for remote sea-state sensing using the Jindalee skywave radar, IEEE Trans. Oceanic Eng., 11, 164, 1986.

Eckersley, T. L.: Irregular ion clouds in the E layer of the ionosphere, Nature, 140, 846-847, 1937.

Farley, D. T.: A plasma instability resulting in field-aligned irregularities in the ionosphere, J. Geophys. Res., 68, 6083-6097, 1963.

Fejer, B. G.: Natural ionospheric plasma waves, Modern Ionospheric Science, 8, European Geophysical Society, edited by Kohl, H., Ruester, R., and Schlegel, K., 216, 1996.

Fejer, B. G. and Kelley, M. C.: Ionospheric irregularities, Rev. Geophys., 18, 401-454, 1980.

Fejer, B. G., Providakes, J., and Farley, D. T.: Theory of plasma waves in the auroral E region, J. Geophys. Res., 89, 7487-7494, 1984.

Fejer, J. A.: Ionospheric instabilities and fine structure, J. Atmos. Terr. Phys., 41, 895-915, 1979.

Haines, M. D. and Reinisch, B. W.: Digisonde portable sounder (DPS) series system technical manual, University of Massachusetts Lowell, Center for Atmospheric Research, Version 3.0, May 1993.

Haldoupis, C., Schlegel, K., and Nielsen, E.: Some observations of radio auroral backscatter at $140 \mathrm{MHz}$ during E-region electron gas heating, Ann. Geophys., 11, 283-295, 1993.

Hanuise, C.: High-latitude ionospheric irregularities: A review of recent radar results, Radio Sci., 18, 1093-1121, 1983.

Harang, L. and Stoffregen, W.: Scattered reflections of radio waves from height of more than $100 \mathrm{~km}$, Nature, 142, 832-833, 1938.

Janhunen, P.: On recent developments in E-region irregularity simulations and a summary of related theory, Ann. Geophys., 13, 791-806, 1995.

Keskinen, M. J. and Ossakow, S. L.: Theories of high-latitude ionospheric irregularities: A review, Radio Sci., 18, 1077-1091, 1983.

MacDougall, J. W., Grant, I. F., and Shen, X.: The Canadian advanced digital ionosonde: Design and results, Ionosonde Networks and Stations, Rep. UAG-104, World Data Center A, 2127, 1995

Maeda, K., Tsuda, T., and Maeda, H.: Theoretical interpretation of the equatorial sporadic E layers, Phys. Rev. Lett., 11, 406-410, 1963.

Monselesan, D. P., Smith, P. R., Morris, R. J., and Dyson, P. L.: Deployment of a Digisonde portable sounder-4 at Casey station, Antarctica, ANARE Res. Notes, 92, 115-134, 1994.

Morris, R. J., Monselesan, D. P., and Klekociuk, A. R.: Australian Antarctic research - a new direction, Adv. Space Res., 16(5), 151-162, 1995.

Morris, R. J., Breed, A. M., Smith, P. R., Papitashvili, V. O., Wallace, S. A., and Hyde, M. R.: A comparison of polar cap 
ionospheric velocity determined from a digital ionosonde model and the DICM and IZMEM/DMSP electric potential models, Adv. Space Res., 33(6), 930-936, doi:10.1016/j.asr.2003.08.013, 2004.

Morris, R. J., Monselesan, D. P., Holdsworth, D. A., Dyson, P. L., Hyde, M. R., and Murphy, D. J.: HF Digisonde and MF radar measurements of E region Bragg scatter Doppler spectral bands under the southern polar cusp, MST10 Workshop Proceedings, Peru, 122-125, 2003.

Olesen, J. K.: A single designation for various gain-sensitive phenomena, INAG Bulletin No. 62, 9, 1998.

Olesen, J. K., Stauning, P., and Tsunoda, R. T.: On a unified interpretation of the polar slant E condition (SEC) and other high E field related phenomena, Radio Sci., 21, 127-140, 1986.

Olesen, J. K., Jacobsen, K. E., Stauning, P., and Henriksen, S.: HF omnidirectional spectral CW auroral radar ("HF-OSCAR") at very high latitude: 1 . Technique, Danish Meteoroligical Institute, Copenhagen, Denmark, 1983.

Parkinson, M. L., Monselesan, D. P., Smith, P. R., Dyson, P. L., and Morris, R. J.: Digital ionosonde measurements of the height variation of drift velocity in the southern polar cap ionosphere: Initial results, J. Geophys. Res., 102, 24 075-24 090, 1997.

Pfister, W. J.: The wave-like nature of inhomogeneities in the Eregion, J. Atmos. Terr. Phys., 33, 999-1025, 1971.

Piggot, W. R. and Rawer, K.: U.R.S.I. Handbook of Ionogram Interpretation and Reduction, Revision of Chapters 1 to 4, Report UAG-12A, World Data Center A for Solar-Terrestrial Physics, 1978.

Providakes, J., Farley, D. T., Fejer, B. G., Sahr, J. D., Swartz, W. E., Häggström, I., Hedberg, Å., and Nordling, J. A.: Observations of auroral E-region plasma waves and electron heating with EISCAT and a VHF radar interferometer, J. Atmos. Terr. Phys., 50, 339-356, 1988.

Rodger, A. S. and Pinnock, M.: The structure of slant Es, INAG Bulletin No. 48, 4-6, 1986.

Sahr, J. D. and Fejer, B. G.: Auroral electrojet plasma irregularity theory and experiment: A critical review of present understanding and future directions, J. Geophys. Res., 101, 26 893-26909, 1996.
Scali, J., Reinisch, B. W., Dozois, C. G., Bibl, K., Kitrosser, D., Haines, D. M., and Bullet, T. W.: Digisonde drift analysis, University of Massachusetts Lowell, Center for Atmospheric Research, 14 July 1995.

Schlegel, K. and St.-Maurice, J. P.: Anomalous heating of the polar E region by unstable plasma waves: 1 . Observations, J. Geophys. Res., 86, 1447-1452, 1981.

Skolnik, M.: Radar Handbook, 2nd Edition, McGraw-Hill Publishing Company, 1990.

Smith, P. R., Dyson, P. L., Monselesan, D. P., and Morris, R. J.: Ionospheric convection at Casey, a southern polar cap station, J. Geophys. Res., 103, 2209-2218, 1998.

Stauning, P.: Absorption of cosmic noise in the E-region during electron heating events. A new class of riometer absorption events, Geophys. Res. Lett., 11, 1184, 1984.

Stauning, P.: Ionospheric radiowave absorption processes in the dayside polar cap boundary regions, Polar Cap Boundary Phenomena, 233-254, Kluwer Academic Publishers, 1998.

Stauning, P., Olesen, J. K., and Tsunoda, R. T.: Observations of the unstable E-region in the polar cap, The Polar Cusp, 365-376, D. Reidel Publishing Company, 1985.

St.-Maurice, J. P., Schlegel, K., and Banks, P. M.: Anomalous heating of the polar E region by unstable plasma waves: 2 . Theory, J. Geophys Rev., 86, 1453-1462, 1981.

Tsunoda, R. T., Perreault, P. D., and Hodges, J. C.: Azimuthal distribution of HF slant $\mathrm{E}$ echoes and its relationship to the polar cap electric field, J. Geophys. Res., 81, 3834-3844, 1976.

Tsunoda, R. T., Olesen, J. K., and Stauning, P.: Radar evidence for a new low-frequency crossed-field plasma instability in the polar mesopause region: A case study, Geophys. Res. Lett., 24, 12151218, 1997.

Wright, J. W. and Argo, P. E.: Chaotic echoes on ionograms: Underdense scattering or total reflections? Radio Sci., 29, 367-384, 1994.

Wright, J. W. and Pitteway, M. L. V.: High-resolution vector velocity determinations from the dynasonde, J. Atmos. Terr. Phys., 56, 961-977, 1994. 